\title{
Tres elementos para una renovación de la práctica sacerdotal
}

\author{
Claudia Leal \\ Facultad de Teología \\ Pontificia Universidad Católica de Chile \\ cleal@uc.cl \\ (1) ORCID: 0000-0002-8180 \\ Fernando Valdivieso \\ Facultad de Teología \\ Pontificia Universidad Católica de Chile \\ ffvaldiv@uc.cl \\ D ORCID: 0000-0001-7188-2811
}

Resumen: En el contexto de una devastadora crisis por abusos sexuales en contexto eclesial, está también la crisis de la figura sacerdotal. Sin descartar la posibilidad de reformular la teología del orden propiamente tal, sostenemos que un buen punto de partida para abordar esta crisis son los aportes de la teología moral contemporánea, y dentro de ella tres herramientas provenientes de las ciencias sociales que pueden aplicarse -con las necesarias adaptaciones- al oficio sacerdotal. Nos referimos al código profesional, a la noción de accountability y a una cierta visión de la vida afectiva del consagrado. Mediante herramientas como estas es posible crear nuevos hábitos que protejan y renueven la espiritualidad sacerdotal, y repercutan positivamente al interior de la comunidad.

Palabras clave: teología moral, crisis de la Iglesia Católica, sacerdocio, ética profesional.

Abstract: In the context of a devastating crisis due to sexual abuse in ecclesiastical context there is also a priesthood crisis. Not dismissing the possibility of reformulating the theology of order, we claim that a effective starting point to meet this crisis is the contribution of contemporary moral theology and within it, three social science instruments, useful -if properly revised- to ministry. Namely professional code, accountability and a certain vision of the affective life of the consecrated person. Through such tools it is possible to create new habits and so to protect and renew priestly practice with a positive impact within the community.

Keywords: moral theology, crises of Catholic Church, priesthood, professional ethics. 


\section{INTRODUCCIÓN}

Este artículo tiene su origen en una experiencia pedagógica llevada a cabo por dos profesores de teología moral y catorce estudiantes del pregrado en teología (laicos y laicas, seminaristas y religiosos), en la cual nos propusimos observar de cerca la experiencia sacerdotal y el modo como esta es vivida en el contexto actual de la comunidad eclesial chilena ${ }^{1}$. A lo largo de un semestre, en el espacio de un curso, intentamos abordar la pregunta ¿Quiénes son los sacerdotes?, con el fin de acercarnos a algunas de las narrativas en las que es presentado el ministerio sacerdotal: narrativas de sacerdotes en primera persona, narrativas de la tradición cristiana y narrativas culturales contenidas en la literatura ${ }^{2}$. Poniendo nuestra mirada en algunos de estos relatos pudimos vislumbrar herramientas que -de la manera más práctica posible- pudieran servirnos como instrumentos para una renovación de la práctica sacerdotal. En las páginas que siguen ahondaremos en tres de estas herramientas: 1) el código profesional, 2) la noción de accountability y 3) la vida afectiva del consagrado. Esperamos que la presentación de estas herramientas sea una contribución concreta a un mejor ejercicio del ministerio ordenado.

El contexto material de nuestra reflexión no debe asociarse exclusivamente a la contingencia de la crisis causada por los abusos sexuales en contextos eclesiales; aunque seguramente su influencia es determinante. En este sentido es necesario atender a la muy citada necesidad de la formación permanente del sacerdote, a la cual este artículo pretende contribuir $^{3}$. Al situarnos en esa formación permanente y mirando el contexto local, constatamos un particular contraste entre un fuerte andamiaje en

1 Las ideas que compartimos en este artículo deben sus conclusiones más importantes al trabajo realizado en el curso "Reflexiones para la renovación de la práctica sacerdotal", impartido por los autores en la Facultad de Teología de la Pontificia Universidad Católica, como parte de las respuestas teológicas a la realidad eclesial local. Vaya nuestro agradecimiento a nuestros estudiantes, que mediante preguntas una reflexión aguda y comprometida, nos ayudaron a vislumbrar nuevas maneras de ser sacerdote hoy.

2 Entre las narrativas examinadas estuvieron: un testimonio bíblico (2 Co 2, 14-7, 4); las cartas de un sacerdote chileno del siglo XIX; los perfiles literarios de sacerdotes en Miguel De Unamuno, San Manuel Bueno y Guillermo Blanco, Gracia y el forastero; el testimonio de un sacerdote joven que atravesó una crisis vocacional.

3 Congregación para el Clero, El don de la vocación sacerdotal, ratio fundamentalis institutionis sacerdotalis (8 diciembre 2016). 
la formación previa a la ordenación ministerial (quizá excesivo) y una brusca ausencia de control y formación durante el presbiterado. Esta constatación alienta nuestra investigación, a través de la cual ofrecemos herramientas concretas para esa etapa permanente de la formación.

Hablamos entonces de la necesidad de una renovación y de su carácter práctico. Otras reflexiones a nivel teórico son, desde luego, importantes, pero nos aparece con una especial urgencia el reclamo de atender a la práctica ${ }^{4}$. Quizás adoptamos aquí implícitamente las reflexiones aristotélico tomistas, que nos persuaden de que los hábitos son los que finalmente modelan la comprensión del mundo; que el propio actuar tiene repercusión sobre nuestra manera de pensar y sobre nuestra cosmovisión. Los hábitos crean o destruyen humanidad. Es que, en efecto, ha sido en la práctica donde se han producido abusos.

Tenemos, por otra parte, la saludable oportunidad de tomar desde las ciencias humanas algunos elementos de la comprensión de la vida práctica que se han desarrollado en las últimas décadas, especialmente en el ámbito de la profesionalización de los oficios. El ministerio sacerdotal, si bien tiene un fuerte contenido vocacional y espiritual que lo hacen irreductible a profesión, puede y debe al mismo tiempo ser profesionalizado.

\section{HaCIA UN CÓDIGO PROFESIONAL DEL SACERDOCIO}

\subsection{El nacimiento de una ética profesional del sacerdocio}

Hace ya un par de décadas venimos escuchando -especialmente en el ámbito anglosajón- la noción de ética profesional del sacerdocio ${ }^{5}$. De frente a un discurso que muchas veces ha hegemonizado la visión del

4 Temáticas e interrogantes tales como el sacerdocio de los viri probati o el sacerdocio femenino no ocupan la reflexión de este artículo. Siendo estos temas relevantes, nuestro foco es ofrecer elementos en el nivel de los hábitos y prácticas sacerdotales, así como estos se dan hoy, con la expectativa de incidir en una mejor vivencia eclesial.

5 Entre los autores que han contribuido a esta reflexión: Sean Cannon, James Keenan, Roberto Noriega. El primero de ellos introdujo de lleno la noción en el ámbito italiano en el 2010, en una conferencia a propósito de la crisis de abusos sexuales en Irlanda (Sean CANNON, "Questo è il momento di agire. La priorità della Chiesa nella tutela dei minori” conferencia Inaugurazione Anno Accademico 2009-2010, Accademia Alfonsiana, agosto de 2009). En el contexto local aparecen los nombres del sociólogo Gabriel Valdivieso, y de Juan Carlos Busenius, quienes sin usar téc- 
sacerdocio desde la perspectiva vocacional -subestimando la visión profesional o de oficio- estas voces nos recuerdan que la dimensión práctica del ministerio sacerdotal está marcada por experiencias que reclaman un discurso más complejo, sofisticado y completo en relación a sus derechos y deberes.

La ética profesional del sacerdocio, probablemente de la mano de las crisis de abusos sexuales en las iglesias irlandesa y estadounidense, puso en el tapete además la dura precariedad en la que se venía desarrollando el ministerio sacerdotal, tanto en un sentido material como psicológico, y la excesiva discrecionalidad que ha acompañado el ejercicio del poder en la práctica sacerdotal.

$\mathrm{Si}$, por una parte, encontramos una natural resistencia a profesionalizar el sacerdocio en aras de su dimensión espiritual-vocacional; por otra parte, el halo espiritual del ministro ordenado ha vuelto excesivamente compleja la fiscalización, supervisión y regulación de su actuar y, como institución, hemos pagado un alto precio por no asumir a tiempo el desafío de enunciar de una manera clara y transparente los derechos y deberes de los protagonistas de la vida eclesial. Es necesario entonces desarrollar una visión de conjunto sobre el ministerio sacerdotal que abra espacios incluyentes de ambas dimensiones, la espiritual/vocacional y la profesional. Desde esta perspectiva, es plausible pensar que una realidad tan propia de la práctica de los oficios y profesiones como son los conflictos de interés puede acontecer también al interior de la comunidad eclesial. Esto es, que sus diversos protagonistas vivan puntos ciegos en relación a la toma de decisiones en el ejercicio de sus funciones y roles. La ética profesional del sacerdocio puede ser comprendida, entonces, como una serie de instrumentos y ejercicios para poner luz en zonas que han estado a la sombra a la hora de actuar. En resumen, se trata de un proyecto ético, que consiste en un ejercicio periódico para discernir la existencia de zonas grises y puntos ciegos, que ponen a prueba el cotidiano despliegue de la vida eclesial.

La cuestión del sacerdocio como profesión tiene probablemente un buen espejo en el ejemplo de la parentalidad: la gran mayoría de las personas experimentamos la paternidad/maternidad como un aspecto

nicamente la expresión "ética profesional del sacerdocio" han puesto el foco de su investigación en las carencias que los sacerdotes viven al desplegar su ministerio. 
omniabarcante de la vida, que marca un antes y un después, que aporta sentido y no admite otro nombre que vocación. Sin embargo, comunitariamente hemos dilucidado a lo largo del tiempo una serie de derechos y deberes relativos a la parentalidad, los hemos normado positivamente, y de no cumplirse estas normas hay consecuencias jurídicas bien claras.

El sacerdocio, en síntesis, posee una dimensión vocacional y una dimensión profesional. Es una forma de vida escogida y, como fruto de la libertad, tiene junto a una dimensión vocacional una dimensión ético profesional, que la hace subordinada a una serie de derechos y deberes, cuyo contenido estamos llamados a resolver comunitariamente, eclesialmente, de la manera más responsable y robusta que podamos. El contenido de la dimensión profesional del sacerdocio no puede ser zanjado por los sacerdotes a puertas cerradas, se trata por el contrario de un balance dinámico que se resuelve en la comprensión de las necesidades, expectativas, ideales y límites que se encuentran presentes en las relaciones que el ministro crea con los demás miembros de la Iglesia y de la sociedad en general.

\subsection{Perspectivas para un código profesional}

Una de las maneras más comunes para dar forma a esta ética profesional del ministerio sacerdotal de la que venimos hablando ha sido la elaboración de códigos profesionales o deontológicos. Al respecto Roberto Noriega señala: "Un código deontológico es un documento que recoge una serie más o menos amplia de principios éticos orientados al correcto ejercicio de una profesión" ${ }^{\text {" }}$. Podemos encontrar su antecedente más remoto en el juramento hipocrático (IV a.C.), la famosa declaración con que Hipócrates busca establecer las prácticas propias de la profesión del médico, distintas a otras prácticas asociadas a la magia, y definir principios éticos fundamentales para el ejercicio de dicha labor, como son: el servicio a la vida, la centralidad del enfermo y el sigilo.

Mediante un código ético profesional se pueden cubrir, entre otras, las siguientes necesidades: 1) unificar las líneas fuerza que definen la ética de una cierta profesión en el colectivo de quienes la ejercen; 2) definir lo que es propio de una cierta profesión, la naturaleza de la profesión; 3)

\footnotetext{
Roberto Noriega, La responsabilidad ética en el ministerio sacerdotal: el arte de servir (Desclée de Brouwer, Bilbao 2016) 341.
} 
establecer las competencias básicas en los profesionales que los capacitan para ejercer; 4) proteger la profesión de individuos no aptos para practicarla; 5) situar la profesión en la sociedad adecuadamente, evitando que se le pida lo que no puede dar; 6) proteger y situar a los miembros de la profesión ante presiones por ejercicios no éticos que se le exijan; 7) delimitar los derechos, expectativas y responsabilidades asociados al ejercicio de la profesión ${ }^{7}$.

De la enumeración anterior emerge que la función del código es doble: por una parte, tiene la función de brindar coordenadas para la regulación que el profesional debe darse a sí mismo (dimensión interna) y, por otra, cumple el objetivo de situarlo en la sociedad, en el terreno de las relaciones habituales que tendrán lugar en el ejercicio de su profesión (dimensión externa).

Un código deontológico para el presbítero es un "instrumento de autorregulación moral" . Constituye una ayuda para guiar a quienes se incorporan al ministerio, al tiempo que purifica las motivaciones de quienes quieran incorporarse, genera un sentido de pertenencia entre el presbiterio (de una cierta diócesis), es un medio de generar confianza ante la vida social y eclesial, ayuda para prevenir conflictos en la medida que supone una toma de conciencia eclesial de las situaciones potencialmente conflictivas en él contenidas, contribuye a apreciar la vocación sacerdotal aumentando la credibilidad social y promueve la responsabilidad personal confrontando al presbítero con su dimensión ética9

Es de notar que la tradición católica latina no carece de antecedentes para fundamentar y proyectar esta argumentación, aunque el volumen y alcance de dichos antecedentes sea más bien minimalista. En efecto, el CIC tiene algunos poquísimos derechos y varios deberes del sacerdote $^{10}$; y los directorios para la vida de los presbíteros y de los obispos

Cf. R. Noriega, La responsabilidad ética, 342.

8 R. Noriega, La responsabilidad ética, 344.

9 R. Noriega, La responsabilidad ética, 344-345. Las cursivas son originales del texto de Noriega.

10 El Código de Derecho Canónico, c. 273-289 establece los siguientes derechos y deberes: 1) Deberes: santidad de vida, relación/obediencia con obispo, fraternidad, formación, pobreza, celibato, residir en la diócesis; 2) Derechos: asociación, remuneración, vacación, a obtener oficio.

Otro aspecto a mencionar del CIC es la renovación del libro penal, cuya reforma lleva años en preparación desde que en 2007 el Papa Benedicto XVI mandatara al 
ofrecen elementos deontológicos, como puede ser la dirección espiritual y la práctica sacramental ${ }^{11}$. Estos directorios son coherentes con la deontología profesional de la que nos hablan hoy las ciencias humanas y sociales; el código deontológico del que hablamos y que proponemos, incluye los elementos que ellos mencionan y ahonda en su contextualización, morigerando elementos exhortativos ${ }^{12}$.

Es de notar entonces que, a pesar del temprano reconocimiento de las bondades de este instrumento, y del tiempo transcurrido desde los primeros escándalos de abusos en contexto eclesial, encontramos un bajo desarrollo. Una razón, dada por Moltmann, es que "los ministros protegemos el statu quo. Tenemos mucho que perder si examinamos nuestra práctica como ministros"13.

\subsection{Algunos aspectos formales de un código profesional del sacerdocio}

En relación a su estructura, tenemos algunos mínimos que sirven como punto de arranque:

- Obligaciones asumidas personalmente: sentido de llamado, conocimiento y habilidades necesarias para ejercer el ministerio, necesidad de formación permanente, necesidad de eliminar conflictos de interés, cuidar la propia salud.

Pontificio Consejo para los Textos legislativos. Ver: David Albornoz, "Consideraciones sobre el proyecto de reforma del Libro VI del Código de Derecho Canónico", Anuario canónico 1 (2015) 361-371.

11 Congregación para el Clero, Directorio para el ministerio y la vida de los presbiteros nueva edición (11 febrero 2013) http://www.vatican.va/roman_curia/congregations/ cclergy/documents/rc_con_cclergy_doc_20130211_direttorio-presbiteri_sp.html. Congregación para los Obispos, Apostolorum Successores, Directorio para el ministerio pastoral de los obispos (22 de febrero de 2004) http://www.vatican.va/ roman_curia/congregations/cbishops/documents/rc_con_cbishops_doc_ 20040222_apostolorum-successores_sp.html.

12 "Catholic priests have not had a professional code of conduct until required to by the Charter for the Protection of Children \& Young People (USCCB, 2002). Traditionally, priests have been guided by canon law, diocesan rules, moral theology, scripture, tradition, and conscience. These sources of guidance are important but were insufficient to prevent or remedy the current crisis." Kane Michael, "Codes of Conduct for Catholic Clergy in the United States: The Professionalization of the Priesthood”, Mental Health, Religion \& Culture 9/4 (2006) 358.

13 R. Noriega, La responsabilidad ética, 348. 
- Obligaciones entre el presbítero y los fieles: confidencialidad, primacía del servicio sobre la remuneración, conocer los límites y fragilidades personales, consultar lo que no sabe, actualizarse, respeto por el otro, fidelidad al Evangelio y a la enseñanza de la Iglesia.

- Obligaciones hacia su ministerio y sus hermanos presbíteros: respeto, disposición a realizar el trabajo en justa distribución, respetar la obediencia.

- Obligaciones hacia la comunidad local y la sociedad en general: mostrarse sensible a los derechos del fiel, ser discreto en publicaciones y solicitudes, ser ejemplo dentro de la ciudadanía.

Adicionalmente, un código de esta naturaleza debe incorporar: 1) quienes juzgan y sancionan a quienes pasen a llevar los límites demarcados; 2) naturaleza de las sanciones y consecuencias, y la violación de las normas del código; 3) órgano o instancia donde las sanciones pueden ser apeladas; 4) delimitación de los sujetos a quienes obliga el código.

Para elaborarlo, Roberto Noriega ${ }^{14}$ recomienda algunas etapas básicas:

- Elección de los principios vitales, los valores que custodiar. Estos serán en relación a Dios y al servicio al Pueblo de Dios.

- Dividir y definir en secciones la vida presbiteral (sacerdote, profeta, rey u otras posibles divisiones).

- Normas concretas. Explicitando los principios vitales en cada una de las secciones. Con especial atención a los ámbitos de mayor vulnerabilidad.

- Concretar los elementos de revisión y renovación del código.

- Establecer concretamente elementos correctivos

Es interesante también recordar que, en el contexto de los primeros avances de la crisis de abusos sexuales, la conferencia episcopal norteamericana determinó en 2002 la necesidad para cada diócesis de establecer códigos de conducta para clérigos y agentes pastorales ${ }^{15}$. Como

4 R. Noriega, La responsabilidad ética, 355-358.

15 "[T]here will be clear and well-publicized diocesan/eparchial standards of ministerial behavior and appropriate boundaries for clergy" (Article 6/ p. 9, de junio 2002, del Charter for the Protection of Children \& Young People de la USCCB); y "Dioceses/eparchies will make clear to clergy and all members of the community the standards of conduct for clergy and other persons in positions of trust with 
respuesta a esta solicitud, el National Catholic Risk Retention Group creó un modelo de código ético para ser adaptado a parroquias, colegios e instituciones de iglesia. El texto está disponible en www.virtus.org ${ }^{16} \mathrm{y}$ se organiza en 1) preámbulo, 2) descripción de responsabilidades 3) lista de diez estándares pastorales y 4) código de conducta del voluntario.

Si bien en algún momento instrumentos tales como el código deontológico fueron criticados por separar al sacerdote del resto de los miembros de la comunidad, e insinuar un horizonte moral más ambicioso que el común a todos los miembros de la institución, es muy probable que hoy, por el contrario, el asumir como vinculante un código profesional ayude al sacerdote a estar en comunión con la mayoría de sus feligreses, quienes en sus profesiones y oficios han desarrollado ya una familiaridad con las diferentes versiones de la ética profesional contemporánea.

\section{ACCOUNTABILITY}

\subsection{Origen del uso del concepto}

Accountability es un concepto anglosajón que puede ser traducido como responsabilización o rendición de cuentas. Se incorpora con fuerza, hace un par de décadas, a las diversas modalidades de discernimiento en la práctica sacerdotal de algunos contextos específicos, con el objetivo de superar una serie de falencias en la responsabilización de los ministros consagrados. En efecto, acaso por un halo de sacralidad que parecía hacer innecesaria una rendición de cuentas por parte del sacerdote, o quizá por un cierto buenismo ingenuo, durante las últimas décadas fueron cayendo paulatinamente en el desuso muchas de las instancias evaluativas existentes, y el hecho es que el presbítero diocesano hoy prácticamente no tiene instancias formales de evaluación; afirmación que vale en multiplicidad de ámbitos: gestión económica, pastoral, personal ${ }^{17}$.

regard to sexual abuse" (Article 12/ p. 12, de junio 2002, del Charter for the Protection of Children \& Young People de la USCCB).

16 https://www.virtusonline.org/virtus/virtus_resources.cfm (consulta: 15/7/2020).

17 Para Hans Zollner, el clericalismo es una de las razones para la ausencia de una adecuada accountability, en la lógica de una sacralidad que envuelve la figura del sacerdote haciéndolo ver como alguien que no necesita justificarse por lo que hace. Hans Zollner, entrevista por Cindy Wooden: "Abuse expert: Crisis is call to new vision of priesthood, accountability" 9/8/2018. 
Se constata además que en la mayoría de los casos, después de la ordenación, un presbítero ejerce tareas muy disímiles entre sí, instalándose una interrogante por la formación específica para esas tareas y otra sobre los criterios para la designación: confesión y acompañamiento, educación, obras sociales, gestión de recursos económicos, gestión de personas, academia, etc. ¿Cómo se evaluará la gestión de esos sacerdotes enviados a tareas tan disímiles si no se han dado las herramientas necesarias para cada gestión, o no se ha cuidado la armonía entre capacidades personales y tareas?

\subsection{Accountability en contexto eclesial}

La accountability conlleva una necesaria responsabilización que alcanza ámbitos estructurales/institucionales así como personales, y adquiere matices específicos según la naturaleza de la comunidad que la adopta. Una suerte de definición de la accountability, muy adecuada para el contexto eclesial, es a nuestro juicio la que nos entrega la canonista italiana Linda Ghisoni (Subsecretaria del Dicasterio para los laicos, la familia y la vida), cuando la explica en los siguientes términos:

"exigencias de carácter social, poniendo a la persona que es investida de responsabilidad ante una rendición de cuentas no solo de frente a sí misma, sino también de frente a la sociedad en que vive y a beneficio de la cual está llamada a desenvolver un determinado encargo"18.

Esto supone la incorporación de instrumentos y procesos para la rendición de cuentas institucional y también la formación personal de una conciencia adulta en el Pueblo de Dios. Este doble plano de la accountability -institucional y personal- presenta desafíos eclesiales concretos a distintos niveles, como son: la responsabilización del ministerio del presbítero y del obispo, más ausente esta última que la del presbítero ${ }^{19}$; la formación de profesionales para el correcto desarrollo de los procesos

https://cruxnow.com/cns/2018/08/abuse-expert-crisis-is-call-to-new-vision-ofpriesthood-accountability/ (consulta: 15/7/20).

18 Linda GHisoni, "Communio: agire insieme" (conferencia en encuentro "La protezione dei minori nella Chiesa”, Ciudad del Vaticano, 22 de febrero de 2019)

http://www.vatican.va/resources/resources_lindaghisoni-protezioneminori_20190222_it.html (consulta: 15/7/2020).

19 Un buen paso en este camino de responsabilización del episcopado es el motu proprio: Francisco, Come una madre amorevole (4 de junio de 2016), Carta apostólica en forma motu proprio, en $A A S 108$ (2016). 
jurídicos (hoy procesos e investigaciones penales están siendo llevadas a cabo por personas formadas en derecho canónico en vistas a la revisión de nulidades matrimoniales y administración de iglesias particulares, y escasamente para cuestiones penales del calibre que hemos visto; el mismo derecho canónico no tiene aún un suficiente desarrollo penal), así como una necesaria educación religiosa que se encamine hacia la formación de cristianos adultos, sensibles y respetuosos de su propia conciencia.

Estos amplios ámbitos de incidencia de la accountability eclesial, junto a su comprensión en el panorama más amplio de otras actitudes necesarias como la transparencia y la compliance ${ }^{20}$, nos remiten a una dimensión cultural. Es decir, cuando hablamos de incorporar la accountability en la vida eclesial no debemos comprender la decisión como un ajuste menor o una palabra mágica que solucione los problemas que nos tienen en la situación de crisis eclesial, no se trata simplemente de redactar protocolos, consiste en cambio en el llamado a una auténtica conversión cultural. Es la cultura eclesial la que tiene que madurar hacia la responsabilización, puesto que el problema tiene un ingrediente fundamental de tipo cultural.

\section{3. ¿Cómo formular una cultura de accountability inspirada en el Evangelio?}

La aplicación de la accountability en la Iglesia, instalada de manera inicialmente confrontacional para exigir a la autoridad eclesiástica la debida responsabilización en los múltiples casos de abusos conocidos en los últimos años ${ }^{21}$, resonó con fuerza en un espacio intraeclesial en febrero de 2019 en Roma, en ocasión del encuentro "La protección de los menores en la Iglesia". Durante dicho encuentro las relaciones de los cardenales Oswald Gracias (arzobispo de Bombay, India), Blase Joseph Cupich (arzobispo de Chicago, USA) y de la ya citada canonista Linda Ghisoni, centraron su exposición en la accountability ${ }^{22}$.

20 Compliance puede ser traducida como: cumplimiento, observancia, acato, ajustado a derecho, cumplimiento de normas o disponibilidad para cumplir expectativas.

21 Un referente en la instalación de este concepto es la organización bishopaccountability.org, que ha nacido con el objeto de denunciar y responsabilizar a obispos en su gestión de los casos de abusos sexuales. En esta misma línea Marie Collins, sobreviviente de abusos clericales en Irlanda, es otra voz que se ha levantado reclamando la necesaria accountability en la iglesia.

22 Cardenal Oswald Gracias, "Responsabilidad (tener que rendir cuentas) en una iglesia colegial y sinodal" (conferencia en encuentro "La protezione dei minori nella Chiesa", 
Ghisoni, en su alocución, refiere la accountability a la naturaleza misma de la Iglesia, en cuanto ella es comunión. En la Iglesia "cada miembro del Pueblo de Dios está exigido y urgido, cada uno según su modo propio, a vivir consecuentemente los derechos-deberes de los que han sido hechos partícipes en el bautismo". Esto implica una adecuada relación entre presbíteros y obispos, así como entre laicos y ministros ordenados. En contraste con la dinámica etnocéntrica de aquella mentalidad que afirma que "solo un obispo sabe lo que es el bien para un obispo, solo un sacerdote sabe lo que es bueno para un sacerdote, solo un laico para un laico, solo una mujer para una mujer", Ghisoni nos propone vivir como verdadera comunidad.

Una relación importante es la que puede establecerse entre la noción de accountability y el principio de sinodalidad. La sinodalidad no es un instrumento funcional al accountability, pero lo favorece y aparece en plena coherencia con él. En un cierto sentido la sinodalidad puede verse fortalecida a través de los mecanismos de la accountability, que les confieren fuerza vinculante a las prácticas de la rendición de cuentas. En efecto, la sinodalidad -aunque debida a toda autoridad- está subordinada a la buena voluntad, discrecionalidad y capacidades del obispo. La accountability, por otro lado, es debida a toda autoridad y, en una institución donde la sinodalidad se erige como principio conductor, su aplicación resulta lógica y necesaria. El Cardenal Oswald reclama para la institución eclesial un sentido colegiado de accountability, reconociendo que esa colegialidad dará lugar inevitablemente a debates e interpretaciones no siempre unánimes sobre las maneras en que se despliega la vida de la comunidad. Advirtiendo, al mismo tiempo que "la colegialidad y la sinodalidad no deben permanecer solo como conceptos teóricos, ampliamente descritos, pero no puestos en práctica”23. Este

Ciudad del Vaticano, 22 de febrero de 2019) http://www.vatican.va/resources/resources_card-gracias-protezioneminori_20190222_it.html (consulta: 15/7/2020).

Cardenal Blase CuPICH, "Sinodalidad: corresponsable" (conferencia en encuentro "La protezione dei minori nella Chiesa", Ciudad del Vaticano, 22 de febrero de 2019) http://www.vatican.va/resources/resources_card-cupich-protezioneminori_20190222_it.html (consulta: 15/7/2020).

Linda GHIsOni, "Communio: agire insieme" (conferencia en encuentro "La protezione dei minori nella Chiesa", Ciudad del Vaticano, 22 de febrero de 2019).

23 "Nell' assumere il nostro collegiale e collettivo senso di accountability (il dover rendere conto) e responsabilità, incontreremo inevitabilmente una certa dialettica" Card. Oswald GraCias, "Responsabilidad (tener que rendir cuentas)" 
es, probablemente, un punto siempre crítico en la gestión institucional, del cual no está exenta la Iglesia: que las declaraciones normativas logren permear las prácticas.

La práctica de la sinodalidad incluye una auténtica corrección fraterna entre obispos, la capacidad de asumir los errores y pedir ayuda (lo que implica la humildad de mostrar vulnerabilidad), así como la posibilidad de rendir cuentas no solo al Papa sino también a los hermanos obispos, sinodalmente.

Ignorar la accountability es ignorar el misterio de la Encarnación. Si no ha de ser por simple negligencia inexcusable, ignorar la accountability es un error antropológico y eclesiológico que no tiene suficiente cuenta de la vulnerabilidad del individuo con un cargo de poder en la comunidad. Muchas veces el ejercicio de la autoridad al interior de las comunidades cristianas ha padecido las consecuencias de una mentalidad que espiritualiza la acción de la gracia en la Iglesia, suponiendo que esa autoridad sabrá cómo actuar en cada momento (inspiración) y hará aquello que sabe debe hacer (santificación).

Es interesante considerar que la accountability es un elemento propio del mundo profesional que está siendo reclamado en el ámbito clerical y eclesial. Que, además, esta noción no viene sola, ella ha de ser insertada en una lógica cultural que incluye la transparencia y la compliance.

Recorrer este camino de conversión cultural en la línea de la responsabilización (y en otras líneas que puedan trazarse) puede llegar a ser un servicio del Pueblo de Dios al mundo. En la medida que lo recorramos ofreceremos un itinerario a la cultura social general para superar una cultura del abuso que trasciende las fronteras eclesiales.

\section{Estatuto Ético de LAS RELACiONES AFECTIVAS: VERTICALIDAD Y HORIZONTALIDAD}

\subsection{Una antropología afectiva a la luz de la tradición cristiana}

Por último, intentemos una reflexión moral sobre las relaciones humanas que el sacerdote despliega, no solo desde su rol sino también como una persona más al interior de sus comunidades de pertenencia. Existe un consenso importante en relación a la necesidad de analizar/ evaluar/observar lo que sucede en el ámbito de la vida afectiva de los 
sacerdotes. Esto en un sentido amplio, no hablamos solo de relaciones románticas o exclusivas, sino de la vital experiencia humana de sentirse parte de una realidad compartida donde la propia individualidad pueda desplegarse en un marco de confianza y seguridad ${ }^{24}$.

Esta experiencia -la de pertenecer existencialmente- admite diversas modalidades. Una manera de caracterizarla puede ser mediante las ideas de verticalidad y horizontalidad. En efecto, nuestra vida afectiva se despliega tanto a partir de relaciones verticales (de admiración, de discipulado, de subordinación, de enseñanza, de acompañamiento, entre otras), como también de aquellas donde estamos de frente a iguales, a pares (amistad, filiación, relaciones laborales, entre otras).

Estos dos ejes -vertical y horizontal- nos sirven para describir nuestra vida afectiva, y además configuran de manera análoga los valores proclamados por la moral cristiana en el ámbito de la sexualidad humana. Así, en la ética sexual cristiana encontramos estos valores en el origen de la sexualidad: procreativo y unitivo ( $\mathrm{Gn} 1,28 ; 2,23)$. No corresponde alargarnos en la discusión de mediados de siglo pasado sobre la posibilidad de una misma realidad (el matrimonio) con dos fines (unitivo y procreativo), simplemente tengamos presente que la incorporación de estos dos valores en el plano afectivo (vertical y horizontal) fueron a lo largo de nuestra tradición motivo de reflexiones y polémicas, en medio de las cuales la antropología cristiana logró hacerse espacio para proclamar la necesidad de conservar el equilibrio de estos dos ejes.

El ser humano, creado a imagen y semejanza de Dios, necesita para su desarrollo integral una doble dimensión en el plano afectivo: la dimensión unitiva y la dimensión generativa.

\subsection{Fecundidad y unitividad en la vida sacerdotal}

Teniendo presentes estos dos ejes de la moral sexual cristiana -unitivo y generativo- proclamados como un llamado antropológico universal, vamos ahora a la vivencia del presbítero, del célibe en general. Aquel que, siguiendo las palabras del Evangelio, abraza el celibato por el Reino de los Cielos (Mt 19, 12), varón o mujer, no deja ni muta su antropología y responde en el plano afectivo al mismo llamado que

24 Véase Kelly Kevin, New Directions on Sexual Ethics (Geoffrey Chapman, London 1998). 
cualquier otro ser humano. Los dos ejes de la afectividad siguen exigiendo, desde dentro del corazón humano, su desarrollo, condición de plenificación de humanidad. Hemos cambiado a propósito el término procreativo por generativo, siguiendo las huellas de la filosofía moral contemporánea (Erich Fromm, Hans Jonas, entre otros) y entendiendo que para célibes y casados este segundo término expresa mejor la imagen de la verticalidad de una parte de la vida afectiva: no se trata tanto de la cuestión biológica de la procreación, sino de la realidad humana de la generación. La vocación cristiana de ser célibes por el Reino, tanto como la vida matrimonial, tendrá que desplegarse siempre en una afectividad vertical y horizontal, y la estructura eclesial no puede atentar contra esta afirmación de la antropología humana. La estructura institucional está llamada, en cambio, a ofrecer espacios seguros donde las personas pueden cultivar sus afectos sin experimentar la propia vulnerabilidad como un defecto o una debilidad.

La necesidad de relaciones horizontales, que abran a la persona a la experiencia de la unitividad, está formulada por Zollner y Cucci en "Iglesia y pedofilia: una herida abierta" 25 . No es raro, afirman estos autores, que el presbítero encuentre dificultad para establecer este tipo de relaciones simétricas. Su rol de autoridad en la comunidad sumado al clericalismo -clericalismo clerical y clericalismo laical- frecuentemente ubican al presbítero en un lugar dentro de la comunidad en el que no tiene ámbitos de relación con pares. Comúnmente está con muchas personas durante gran parte del día, pero con todas ellas tiene una relación de referente espiritual, de encargado de pastoral, de jefe o de mentor $^{26}$. No es raro que a veces se cree la ilusión de la horizontalidad, especialmente cuando el sacerdote se mimetiza con la comunidad que acompaña y aparentemente llega a ser uno más, dando paso a una cierta ambigüedad ética en las relaciones propiamente pastorales y a una vida interior vivida en soledad y aislamiento.

En la propuesta de vida conyugal el equilibrio de los ejes vertical y horizontal de la afectividad está más o menos bien resuelto en el matrimonio cristiano. Pero en la consagración célibe no se puede decir lo

25 G. CuCCI - H. Zollner, Iglesia y pedofilia: una herida abierta: Una aproximación psicológico-pastoral (Sal Tarrae, Santander 2010).

26 Véase Michael PAPESH, Clerical Culture: Contradiction and Transformation (Liturgical Press, Collegeville 2004). 
mismo, sobre todo por el ámbito horizontal. Las comunidades que viven la fraternidad, al menos en el ideal, tienen resuelta la propuesta del eje horizontal, pero el presbítero diocesano, no. Más allá de la declaración de fraternidad en el presbiterado por el vínculo sacramental que une a los presbíteros de una diócesis ${ }^{27}$, no aparece una propuesta eclesial contundente para aquellos que, experimentando el llamado del Señor a seguirlo en el ministerio ordenado, se consagran en la Iglesia célibes por el Reino.

Insistimos en la relevancia de una justa comprensión de la importancia de la dimensión horizontal de la afectividad no solo por los relatos de dobles vidas y costos psicológicos del ejercicio sacerdotal, sino también porque, en las pocas investigaciones de las cuales disponemos sobre la experiencia de quienes han cometido abusos al interior de la comunidad eclesial, se constata de manera recurrente la ilusión patológica de horizontalidad (Mary Keenan ${ }^{28}$ ) y en los casos de abusos a mujeres esta ilusión patológica es expresada en términos de enamoramiento.

El sacerdote trabaja con los afectos, ellos son en un cierto sentido su instrumento de trabajo. Podría expresarse, entonces, el imperativo de una madurez afectiva necesaria para el ejercicio del ministerio, y de hecho este imperativo es exigido en la formación sacerdotal y en la elección de los candidatos. Pero eso no basta. Los desafíos psicoafectivos son contextuales, tanto en un sentido biográfico como cultural, y los desafíos que un sacerdote experimenta en la formación no son los mismos que deberá abordar en las crisis de la madurez. Por lo tanto, sería adecuado comprender la formación psicoafectiva como un "entrenamiento ético metodológico” más que como la incorporación de contenidos.

La cuestión que nos interesa poner al centro de la conversación es de qué manera el presbítero diocesano, que ha abrazado la vida célibe por el Reino de los Cielos, encuentra el necesario desarrollo de las dos dimensiones de su afectividad: horizontal y vertical, unitiva y generativa. La dimensión generativa es evidente en el plano pastoral y espiritual, no por nada se les llama "padres" en Chile. También la puede encontrar en el plano intelectual, en causas sociales, en la formación, etc. Pero las

27 Concilio Ecuménico Vaticano II, Presbyterorum ordinis (7 diciembre 1965), Decreto sobre el ministerio y la vida de los presbíteros, en $A A S 58$ (1966), 8.

28 Marie Keenan, Child Sexual Abuse and the Catholic Church: Gender, Power, and Organizational Culture (Oxford University Press, New York 2012). 
posibilidades de desarrollo de la dimensión horizontal son más difusas y es urgente abordarlas.

\section{Conclusión}

La pregunta ¿quiénes son los sacerdotes? que nos inspiraba al inicio de esta reflexión, es una interrogante que permanece abierta, que no debiera ser rápidamente descartada en la teología contemporánea, y que reclama una respuesta a nivel identitario. Creemos que la identidad del sacerdote es un elemento dinámico que, en diálogo con la consolidación y maduración de la identidad humana, configura una respuesta personal y eclesial capaz de interpelar tanto a la cultura como a los miembros de la institución. En otras palabras, el hecho de que la identidad sacerdotal sea dinámica reclama una atención y acompañamiento a lo largo de la historia personal y comunitaria.

Los tres elementos para la renovación de la práctica sacerdotal que aquí ofrecemos se enmarcan en el desafío eclesial más amplio de la formación permanente del clero. Se constata, en efecto, que la formación inicial de los presbíteros ha sido atendida con dedicación en los últimos años en la Iglesia, incorporando con más fuerza elementos humanos y afectivos, así como itinerarios y herramientas para una formación integral ${ }^{29}$. En cambio, la formación permanente del clero no ha tenido todavía una intervención consistente en este sentido, quedándose circunscrita, en muchos casos, a actualizaciones teológicas y retiros espirituales. Una auténtica formación permanente del ministro ordenado debe atender a las cuatro dimensiones formativas que estructuran la formación inicial: humana, espiritual, pastoral e intelectual. Un plan de formación que aborde estas dimensiones considere etapas y ofrezca herramientas, ayudará a profesionalizar el ejercicio del ministerio, evitando la brecha entre una formación inicial robusta (quizá a veces en exceso) y un diluido acompañamiento durante el ejercicio del ministerio. Los elementos ofrecidos en este artículo van en la línea de esa formación permanente integral.

La identidad sacerdotal es demandada y desplegada en ámbitos tan disímiles como la educación, la gestión económica y el acompañamiento

29 Hito importante en el positivo desarrollo de la formación inicial para el presbiterado en los últimos años es la Ratio Fundamentalis Institutionis sacerdotalis "El don de la vocación presbiteral”, de diciembre de 2019. Así como las distintas ratio nationalis que se están preparando en cada país. 
espiritual; hemos afirmado que implementar evaluaciones justas es importante para brindar al sacerdote y a la comunidad marcos compartidos en relación con derechos, deberes y actitudes, que construyan un marco de acción común donde las relaciones puedan desarrollarse en base a la confianza recíproca. A través de herramientas como las que hemos presentado en estas páginas, y también otras, podemos crecer en la tarea de poner en primer lugar la dignidad de todos quienes buscan en la Iglesia una experiencia de auténtico encuentro con Dios. 